\title{
AVALIAÇÃO SENSORIAL DE PÊSSEgOS OBTIDOS POR DIFERENTES MÉTODOS DE SECAGEM
}

\author{
M. E. BALKE ${ }^{1}$, H.T. OLIVEIRA ${ }^{1}$, C. STEFFENS ${ }^{2}$, E. VALDUGA ${ }^{2}$, A.B.J.SOARES ${ }^{3}$, J. \\ STEFFENS $^{2}$, M.B.A. SOARES ${ }^{2}$ \\ ${ }^{1}$ Instituto Federal Ciência e Tecnologia Rio Grande do Sul, Campus Erechim. \\ ${ }^{2}$ Universidade Regional Integrada do Alto Uruguai e das Missões, Departamento de Ciências \\ Agrárias. \\ ${ }^{3}$ Universidade Regional Integrada do Alto Uruguai e das Missões, Departamento de Ciências exatas e \\ da Computação \\ E-mail para contato: marlova.balke@erechim.ifrs.edu.br
}

\begin{abstract}
RESUMO - O objetivo do estudo foi analisar secagem convencional com ar quente em estufa, com Desidratação Osmótica (DO) seguido de secagem em estufa e liofilização com as cultivares de pêssego Chimarrita e Eragil na aceitação sensorial do produto. Para secagem em estufa, as fatias da fruta foram colocadas em bandejas na de circulação de ar a $60^{\circ} \mathrm{C}$ permanecendo até apresentarem peso constante, onde Chimarrita apresentou 5,5h de secagem e 160g de massa; enquanto na Eragil obteve-se $196 \mathrm{~g}$ em $7 \mathrm{~h}$. Na DO seguida de secagem por estufa, colocou-se os pêssegos das duas variedades por $2 \mathrm{~h}$ em banho-maria a $30^{\circ} \mathrm{C}$ com $45^{\circ}$ Brix, e posterior emente colocou-se em estufa a $60^{\circ} \mathrm{C}$, até peso constante. Com a variedade Chimarrita, o tempo de secagem foi $7 \mathrm{~h}$ e $237 \mathrm{~g}$; enquanto Eragil foi de $6,5 \mathrm{~h}$ e $320 \mathrm{~g}$. Para a liofilização, as cultivares foram colocadas por $16 \mathrm{~h} \mathrm{a}-80^{\circ} \mathrm{C}$ e posteriormente liofilizadas a $-60^{\circ} \mathrm{C}$, onde permaneceram por $46,5 \mathrm{~h}$ e ao final do processo, Chimarrita apresentou $120 \mathrm{~g}$, enquanto Eragil 191g. Pode-se verificar com relação a aceitabilidade, que a cultivar Eragil com DO seguida de secagem em estufa teve melhor aceitação sensorial em relação a outros processos, assim como preferência de compra.

Palavras-chave: Desidratação, Liofilização, Secagem, Pêssego, Aceitabilidade.
\end{abstract}

\section{INTRODUÇÃO}

A grande maioria dos alimentos sofre deterioração com muita facilidade, por isso diante desse problema, surgiram algumas técnicas de conservação dos alimentos, dentre os quais a secagem é uma das mais utilizadas. Muitas são as vantagens da secagem tais como: conservação do produto e a redução do seu peso, com a consequente redução do custo de transporte e de armazenamento em relação aos produtos enlatados e congelados. Com a secagem, ao diminuir a quantidade de água, ocorre não só a redução do peso, como também, cria-se condições desfavoráveis para o crescimento microbiano no produto. Além disso, a secagem é utilizada para 
reduzir o custo ou dificuldade de embalagem, manuseio, armazenamento e transporte através da conversão de alimentos em forma de um sólido seco (ORIKASA et al., 2013).

Alguns produtos, quando submetidos à secagem, conservam bastante intactas suas características físicas e nutritivas e retornam ao aspecto natural ou sofrem poucas alterações quando reconstituídos em água. Assim, este processo representa uma forma viável de conservação de alimentos para consumo humano. Os alimentos desidratados podem ser consumidos diretamente, como por exemplo, figos secos, banana-passa, uva-passa etc. (CORNEJO; NOGUEIRA. WILBERG, 2003). Nesse sentido, os diferentes processos de secagem de frutas corroboram para obtenção de produtos com melhor qualidade e vida útil. A secagem por liofilização, desidratação osmótica seguida por secagem em estufa, e secagem em estufa para desidratação de frutas, são métodos alternativos que podem trazer muitos benefícios, incluindo melhoria na qualidade de pêssegos desidratados (MARZEC et al., 2010). Vale salientar, que a secagem exige uma escolha de parâmetros adequados para desidratação das frutas.

A produção de pêssego é uma atividade significativa para os produtores no Rio Grande do Sul, no entanto devido a sua sazonalidade percebe-se a necessidade de variadas técnicas para sua conservação, como também a viabilidade de melhoras econômica aos produtores. Como matériaprima de qualidade diferenciada, o pêssego pode proporcionar a eles novas e diferentes fontes de renda, beneficiando dessa forma a economia regional. A oferta de pêssegos in natura no Brasil ocorre nos meses de novembro a março. Os pêssegos também são consumidos durante o ano todo na forma de sucos, doces, geleias, compotas e adicionados aos iogurtes. No entanto, não se produz pêssego desidratado em escala comercial no Brasil. Considerando o alto valor agregado das frutas secas encontradas no mercado, e o fato de parte importante das mesmas ser importadas, a alternativa de se obter novas frutas secas precisa de novos dados e estudos. Sendo fruto climatérico, o pêssego tem metabolismo acelerado e gera perdas pós-colheita que alcançam de 30 a 50\% da produção (DI RIENZO, 2001). Embora o Brasil seja o terceiro maior produtor mundial de frutos in natura (SEBRAE, 2005), importa 172.000 toneladas de frutas desidratadas e exporta apenas 12.000 toneladas (FAO, 2005). A desidratação de pêssegos pode contribuir para a minimização das perdas e possibilitar agregação de valor ao fruto.

Dessa forma, com a constante necessidade de crescimento, inovação e competição, é de grande relevância para a agricultura regional o desenvolvimento de estudos na área de secagem de frutas, permitindo à agregação de valor ao produto e obter melhor competitividade no mercado. Neste sentido, o presente trabalho visa a avaliação sensorial de pêssego obtidos por secagem.

\section{MATERIAIS E MÉTODOS}

\subsection{Secagem dos pêssegos}


O processamento do pêssego foi realizado na usina piloto de Frutas e Hortaliças da Engenharia Alimentos (URI-Erechim), onde os frutos da variedade Chimarrita e Eragil foram selecionados, lavados e fatiados e imediatamente imersos em ácido cítrico a 1\% durante 1 min. Após foi realizado o branqueamento, onde as frutas foram mantidas submersas em água quente $\left(80^{\circ} \mathrm{C}\right)$ por $10 \mathrm{~min}$, e posteriormente deixadas em ar ambiente para esfriar. A Figura 1 apresenta a variedade de pêssego chimarrita, enquanto que a Figura 2, a variedade eragil:

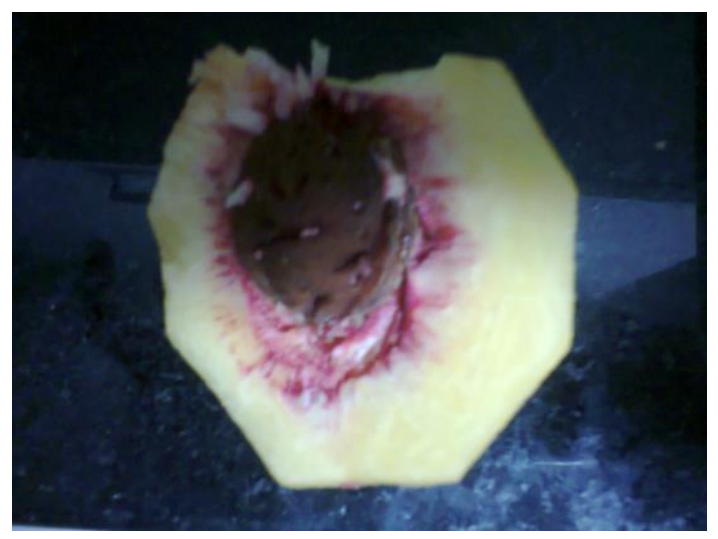

Figura 1- Variedade de pêssego chimarrita.

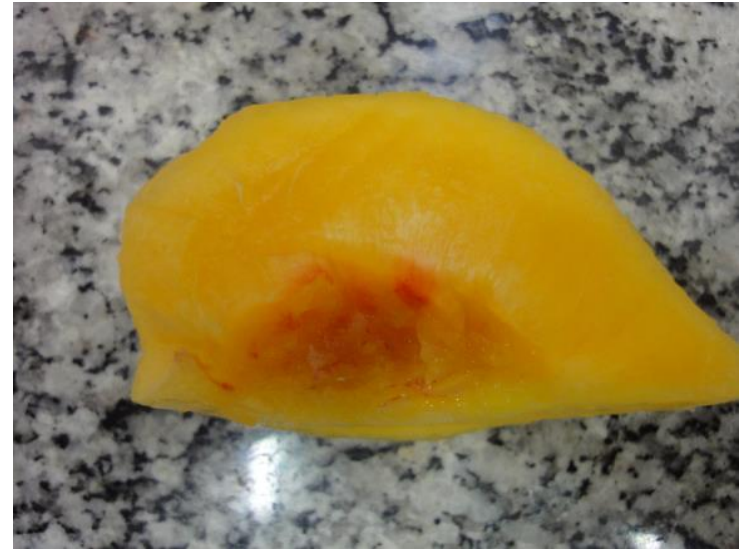

Figura 2- Variedade de pêssego eragil.

Para o processo de secagem foram utilizados três métodos: secagem em estufa, com DO seguida de secagem em estufa e liofilização. A desidratação osmótica foi realizada ao abrigo condições de pressão atmosférica em agitação, utilizando-se solução de sacarose $\left(45^{\circ}\right.$ Brix) e $30^{\circ} \mathrm{C}$ por um período de $60 \mathrm{~min}$. Posteriormente, os pêssegos foram dispostos em bandejas e 
desidratados em estufa (Marconi, modelo MA 037, Brasil) a $60^{\circ} \mathrm{C}$ sendo efetuadas medidas de peso a cada 30 min., até atingirem peso constante.

Na secagem somente em estufa, os pêssegos das duas variedades foram dispostos em bandejas dentro de uma estufa (Marconi, modelo MA 037, Brasil) a $60^{\circ} \mathrm{C}$ sendo efetuadas medidas de peso a cada $30 \mathrm{~min}$, até atingirem peso constante.

Para o processo de liofilização os pêssegos foram: cortados em fatias $(1,5 \mathrm{~cm})$, as quais então revestidas com papel alumínio e congeladas a $-80 \pm 2^{\circ} \mathrm{C}$ durante $12 \mathrm{~h}$. Após essas etapas, as amostras colocadas no liofilizador a $-60^{\circ} \mathrm{C}$ por um período de $46,5 \mathrm{~h}$.

\subsection{Análises Físico químicas}

Das variedades dos pêssegos, Chimarrita e Eragil in natura que passaram pelos diferentes processos de secagem, foram realizadas análises de umidade e $\mathrm{pH}$, através das metodologias Instituo Adolfo Lutz (IAL, 2008) e AOAC (1995), respectivamente.

\subsection{Análise Sensorial}

Os pêssegos, que passaram pelos diferentes processos de secagem, foram analisados sensorialmente, em que na avaliação sensorial, foi realizado o teste de aceitação, com provadores não treinados, sendo utilizados grupos de no mínimo trinta provadores. Os provadores avaliaram o quanto gostaram ou desgostaram das amostras, através de uma escala hedônica de nove pontos com os extremos correspondendo a: "desgostei extremamente" (1) e "gostei extremamente" (9). Além disso, foi verificada também a intenção de compra dos produtos utilizando-se uma escala de cinco pontos, variando do certamente compraria (5) ao certamente não compraria (1) (DUTCOSKY, 2007).

\subsection{Análise estatística}

O programa Statistica ${ }^{\circledR}$ (StatSoft, USA), foi usado para calcular as diferenças significativas entre as propriedades de todas as amostras, no intervalo de $95 \%$ de confiança.

\section{RESULTADOS E DISCUSSÕES}

Na secagem com desidratação osmótica (DO) com posterior uso de estufa, observou-se que a variedade Chimarrita apresentou um tempo de $7 \mathrm{~h}$ para a secagem resultando em $237 \mathrm{~g}$ de massa; enquanto que a variedade Eragil resultou em $320 \mathrm{~g}$ de massa num período de 6,5 h. Para o processo de secagem em estufa, a variedade Chimarrita apresentou 5,5 h e $160 \mathrm{~g}$ de massa; enquanto que Eragil resultou em $196 \mathrm{~g}$ de massa em $7 \mathrm{~h}$ de processo. Já para o processo de liofilização após $46,5 \mathrm{~h}$ a $-60^{\circ} \mathrm{C}$ e a pressão de $62 \mu \mathrm{Hg}$ a massa final para a variedade Chimarrita foi de $120 \mathrm{~g}$, enquanto que para a variedade Eragil foi de $191 \mathrm{~g}$. 
Ao analisarem-se os dados de peso final das amostras, verifica-se que a secagem por liofilização apresenta massas menores ao final do processo, comparados aos outros dois métodos. $\mathrm{O}$ processo que obteve maior quantidade de massa ao final foi secagem com desidratação osmótica (DO) com posterior uso de estufa.

$\mathrm{Na}$ Tabela 1 são apresentados os valores de umidade e de $\mathrm{pH}$ das variedades de pêssego in natura e nos diferentes processos de secagem. Verifica-se que a variedade Chimarrita com processo de liofilização apresentou menor teor de umidade, $\mathrm{pH}$. Este processo com este tipo de pêssego resultou também em menor massa final (120g) devido apresentar menos umidade $(15,17 \%)$ e a varidade Eragil com processo de DO e estufa apresentou no final do processo maior teor de umidade $(26,35 \%)$ como também, teve maior peso final $(320 \mathrm{~g})$. A determinação da umidade é uma das medidas mais importantes na análise de alimentos, pois está relacionada com a sua estabilidade, qualidade e composição (CHAVES et al., 2004).

A legislação vigente para produtos liofilizados (Resolução CNNPA $n^{\circ} 12$ ) estabelece que produtos liofilizados obtenham máximo de $5 \%$ de umidade (BRASIL, 2008). Neste sentido os valores de umidade encontrados para o processo de liofilização neste trabalho estão fora da legislação e precisam, portanto, em trabalhos futuros minimizar estes valores, por meio de métodos alternativos.

Tabela1- Valores de umidade e de $\mathrm{pH}$ das variedades de pêssego in natura e após os diferentes processos de secagem.

\begin{tabular}{lcc}
\hline Variedade/Processo & pH & Umidade (\%) \\
\hline Chimarrita/ in natura & 5,53 & 88,33 \\
Chimarrita/DO e estufa & 3,78 & 24,54 \\
Chimarrita/somente estufa & 4,08 & 25,95 \\
Chimarrita /liofilização & 3,19 & 15,17 \\
Eragil/in natura & 5,90 & 88,61 \\
Eragil/DO e estufa & 4,11 & 26,35 \\
Eragil/somente estufa & 4,60 & 23,04 \\
Eragil/liofilização & 4,55 & 16,35 \\
\hline
\end{tabular}

Os resultados da análise sensorial com relação à aceitação, são mostrados na Tabela 2, em que são apresentadas as amostras, classificadas como: A (cultivar Eragil com processos de secagem em estufa), B (cultivar Chimarrita com processos de prévia DO e posterior secagem em estufa), C (cultivar Eragil com processo de prévia DO e posterior secagem em estufa), D (cultivar Chimarrita com processos de secagem em estufa), E(Chimarrita liofilizado), F (Eragil liofilizado).

Pode-se verificar que a maior pontuação dada pelos provadores foi para o tratamento de secagem do pêssego Eragil (amostra C) e o tratamento com menor aceitação foi o "D" para a variedade Chimarrita liofilizada. A melhor aceitação pode ser devida a variedade Eragil que foi 
do processo com DO seguida de secagem em estufa, a qual apresentou maior umidade, o que pode ter proporcionado melhores condições organolépticas. O processo com menor aceitação, que foi com a secagem em estufa e a varidade Chimarrita, pode ser devido a este tipo de processamento não proporcionar características sensoriais adequadas e também devido a própria varidade de pêssego.

Tabela 2 - Média das pontuações dos provadores (desvio padrão) na análise sensorial de aceitação geral dos processos de secagem de pêssego

\begin{tabular}{cc}
\hline Amostra & Pontuação \\
\hline A & $6,34^{\text {abd }} \pm 1,37$ \\
B & $7,17^{\text {abd }} \pm 1,58$ \\
C & $7,47^{\mathrm{ad}} \pm 1,50$ \\
D & $4,81^{\mathrm{bc}} \pm 1,52$ \\
E & $5,15^{\mathrm{bcd}} \pm 1,95$ \\
F & $5,37^{\mathrm{cd}} \pm 2,08$ \\
\hline
\end{tabular}

$* \mathrm{M}(\mathrm{DV})=$ Média das pontuações \pm desvio padrão seguidas de letras iguais não diferem estatisticamente à nível de $5 \%$ (Teste de Tukey).

Observa-se também que estatisticamente há diferença significativa entre as amostras "C" e "D”, as quais são da variedade Eragil, por processo com DO seguida de estufa e variedade Chimarrita com processo de secagem em estufa. As outras amostras não tiveram diferença significativa entre elas.

Os resultados em relação à intenção de compra são mostrados na Figura 3. Observa-se que a amostra "C" teve melhor preferência de compra, seguido pela amostra "B", "A", "D", "F".

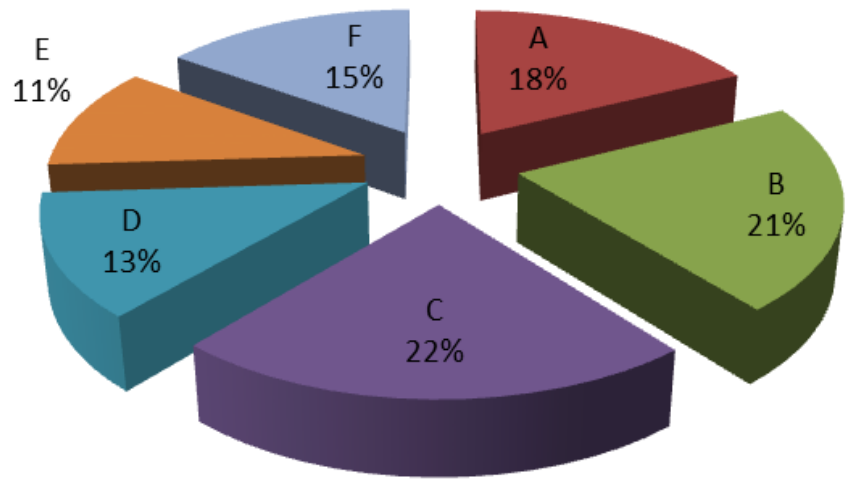

Figura 3- Preferência de compra das amostras de pêssego em diferentes tipos de secagem. 


\section{CONCLUSÕES}

O processo de resultou maior peso final e aceitabilidade foi o de DO seguido de estufa o que também apresentou maior umidade final.

Pode-se concluir que desidratação é fator relevante no processamento e conservação de pêssego, visto que remove parcialmente o conteúdo de água, em que os pêssegos eragil, com prévio tratamento osmótico, seguido de secagem convectiva apresentou maior aceitabilidade diante dos outros processos como também, verificou-se que é necessário maior estudo com as variedades de pêssego analisadas e com relação aos processos de secagem.

\section{REFERÊNCIAS BIBLIOGRÁFICAS}

ASSOCIATION OF OFFICIAL ANALYTICAL CHEMISTS (AOAC). Official Methods of Analysis of AOAC International. 16. ed. Washington, v.1-2, 1995.

BRASIL. Ministério da Saúde. Agência Nacional de Vigilância Sanitária. Resolução - CNNPA $n^{\circ}$ 12, de 24/de julho de 1978. Disponível em: www.anvisa.gov.br acessado em 05/05/2014.

CHAVES, M.C.V. et al. Caracterização físico-química de suco de acerola. Rev. Biol. Cien. Terra. Vol. 4. n2, 2004.

CORNEJO, F. E; NOGUEIRA, R. I.; WILBERG, V. C. Secagem como método de conservação de frutas. Embrapa Agroindústria de Alimentos. Documentos 54, Rio de Janeiro, 2003.

DI RIENZO, C. A importância das câmaras frias na horticultura. Tecnologia da Refrigeração, $\mathrm{n}$. 5, p. 16- 22, 2001.

FAO. Food and Agriculture Organization of the United Nations. FAO Statistical Databasis. Disponível em: <http:// www.todafruta.com.b>r. Acesso em: 12 março.2014.

IAL -Instituto Adolfo Lutz -. Métodos Físico-Químicos para análise de alimentos. São Paulo, IV Edição 1. Edição Digital, 2008.

MARZEC, A.; KOWALSKA, H.; ZADROŻNA, M. Analysis of instrumental and sensory texture Attributes of microwave-convective dried apples. Warsaw University of Life Science, Faculty of Food Sciences Department of Food Engineering and Process Management.ul. Nowoursynowska Warsaw, 2010. Disponível em: <http://www. onlinelibrary.wiley.com/doi/10.1111/j.1745-4603.2010.00234.x/pdf >. Acesso em 28 de dezembro de 2013.

ORIKASA, T. et al. Impacts of hot air and vacuum drying on the quality attributes of kiwifruit slicesma Contents lists available. Journal of Food Engineering. 2013. Disponível em: <http://www.elsevier.com/locate/jfoodeng.> 
Acesso em: 16 dezembro 2013.

SEBRAE. Serviço Brasileiro de Apoio às Micro e Pequenas Empresas. Classificação das MPEs segundo o número de empregados. Disponível em: <http://www.sebraesc.com.br/leis/ default.asp?vcdtexto=4154>. Acesso em 20 abril 2014. 